\title{
A EXPERIÊNCIA DE UMA FORMADORA DE PROFESSORES DE QUÍMICA: ANALISANDO SUAS AÇÕES E REFLEXÕES NUM CURSO DE EDUCAÇÃO CONTINUADA
}

\section{The experience of a chemistry teacher educator: analyzing their actions and reflections in a continuing education course}

\author{
Maisa Helena Altarugio ${ }^{1}$ \\ Alberto Villani ${ }^{2}$
}

\begin{abstract}
Resumo: Objetivou-se analisar a experiência de uma formadora num curso de formação continuada para professores de Química, ocorrido numa universidade pública do estado de São Paulo, em 2004. Os dados apresentados surgiram da observação da prática da formadora e de suas reflexões, nas quais ela própria evidencia ideias, conflitos, angústias e impressões sobre suas ações durante o curso. Entre a prática da formadora e suas reflexões, surgem contrastes que irão se tornar nosso foco de investigação. Interpretamos esses contrastes como a atuação de elementos inconscientes que ora favorecem ora dificultam a sua prática e nos mostram que nem sempre a reflexão e a ação atuam na mesma direção. Defendemos uma prática reflexiva mais profunda e questionadora dos sujeitos como possibilidade para produzir melhores efeitos na formação e na atividade docente. Conceitos do referencial teórico psicanalítico de Freud e Lacan serviram de base para a análise dos dados.
\end{abstract}

Palavras-chave: Formação continuada de professores. Papel do formador. Educação e psicanálise. Reflexão docente.

\begin{abstract}
This paper is meant to analyze a teacher educator's experience when giving a continuing education course for chemistry teachers, held at a public university in São Paulo, in 2004. The information here has resulted from the observation of the teacher educator's performance and her reflections on their own ideas, conflicts, anguish and impressions concerning her actions throughout the course. The contrasts between the educator's practice and her reflections are the focus of this study. Such contrasts are regarded as a result of the presence of unconscious elements that either favor or hinder practice, and show that reflection and action not always lead to the same direction. We believe individuals should be encouraged to take a more questioning and more reflective attitude, enabling better results in teachers' education as well as more effective performance. Data analysis was based on concepts belonging to Freud's and Lacan's psychoanalytic theories.
\end{abstract}

Keywords: Teacher's continued education. Teacher educator's role. Education and psychoanalysis. Teachers' reflection.

\footnotetext{
${ }^{1}$ Licenciada em Química, doutora em Ensino de Ciências. Docente, Curso de Licenciatura em Química, Centro de Ciências Naturais e Humanidades, Universidade Federal do ABC (UFABC). Santo André, SP, Brasil. <maisa.altarugio@ufabc.edu.br>

${ }^{2}$ Licenciado em Filosofia, doutor em Física. Docente, Departamento de Física Aplicada, Instituto de Física, Universidade de São Paulo (USP). São Paulo, SP, Brasil.<avillani@if.usp.br>

${ }^{1}$ Centro de Ciências Naturais e Humanidades - UFABC

Av. dos Estados, 5001

Santo André, SP

$09.210-971$

595

Ciência \&̊ Educação, v. 16, n. 3, p. 595-609, 2010
} 
Altarugio, M. H.; Villani, A.

\section{Introdução}

Muitas pesquisas em ensino de ciências têm apontado e determinado exigências em relação aos conhecimentos teóricos e práticos desejáveis aos professores no exercício de sua função de ensinar. O trabalho de Sánchez Blanco e Valcárcel Pérez (2000), por exemplo, elenca alguns desses saberes, tais como: conhecer em profundidade a sua disciplina; saber detectar, analisar e interpretar as concepções dos alunos; conhecer a psicologia e a sociologia do adolescente; ter critérios para seleção e sequenciação de conteúdos. Além desses, podemos acrescentar a preocupação com o desenvolvimento do profissional crítico e reflexivo (PERRENOUD, 1993) e de habilidades do tipo metacognitivo (GUNSTONE; NORTHFIEL, 1994).

Vários modelos de formação continuada, citados por Copello Levy e Sanmartí Puig (2001), propõem-se a trabalhar os conhecimentos desejáveis aos professores. Os autores organizam esses modelos segundo duas tipologias: aqueles que se caracterizam por tratarem de temas específicos, cuja integração ao espaço de atuação fica por conta de cada professor; e aqueles cuja finalidade é transformar as práticas dos professores; estes últimos, geralmente, ocorrem nos próprios locais de trabalho e tentam promover a reflexão epistemológica e psicopedagógica, relacionando-a com a área específica do conhecimento. Os autores assinalam também que, apesar das vantagens e da larga extensão da aplicação deste modelo nos últimos anos, poucas mudanças têm sido observadas.

Em outra pesquisa (ALTARUGIO, 2002), podemos encontrar várias pistas das dificuldades dos professores em realizar mudanças efetivas em suas práticas. A natureza dessas dificuldades, apontada pelos próprios professores, mostra que fatores externos ao professor - tais como: ausência de laboratório ou equipamentos adequados nas escolas, alunos desinteressados e indisciplinados, falta de apoio dos colegas e da direção da escola, número insuficiente de aulas, salas de aulas muito lotadas - e fatores internos ao professor - como a dificuldade de abandonar os vícios do ensino tradicional e a insegurança diante de novas propostas - ainda se configuram obstáculos trazidos para o interior dos cursos de formação continuada.

Procurando outras variáveis para explicar o lento processo de mudança nas práticas de ensino, Copello Levy e Sanmartí Puig (2001) ainda mencionam a desarmonia entre o interesse das administrações públicas em mostrar resultados imediatos, que primam pela quantidade ao invés de qualidade, e o fato de a formação dos professores exigir tempo e se efetivar a longo prazo.

Apesar de endossarmos todas as pesquisas já produzidas nesse campo de investigações, achamos que é possível buscar, dentro do próprio curso de formação e, especificamente, no papel que o formador exerce no processo, uma contribuição significativa e não menos importante que o do próprio professor em formação. As atitudes e a postura do formador em relação aos professores - como ele se sensibiliza, detecta, conduz e lida com as dificuldades dos professores - parecem ser decisivas para a qualidade dos resultados que se obtêm nos cursos de formação.

Assim como o professor que ele pretende educar, o formador também traz consigo suas crenças, suas experiências pessoais e modelos que incorporou ao longo de sua própria formação e caminhada como profissional. Esse formador, além de um educador, precisa ser visto como um sujeito que também enfrenta dificuldades em sua prática, que se submete a riscos, que se encontra cindido, ora entre sua inteligência e sua intuição, ora entre seus medos e seus desejos, vítima de seus contrastes. 
Quando Lajonquière analisa um erro de uma aluna como sintoma, ou seja, como "indício de alguma coisa" (aspas do autor), ele se propõe $a$ "entender as vicissitudes que um sujeito suporta na sua aprendizagem (ou seja, as marchas e contramarchas) como sendo produtos sobredeterminados da inteligência e do desejo inconsciente" (LAJONQUIÈRE, 1992, p. 148). Aqui, o autor se apoia na psicanálise para afirmar que "as vicissitudes nas aprendizagens (das quais o erro não é mais do que um dos seus disfarces) são funções dos acidentes simbólicos próprios da constituição de uma subjetividade" (LAJONQUIĖRE, 1992, p. 149). Numa analogia ao formador de professores, as vicissitudes na sua tarefa de formar também podem ser analisadas de forma semelhante, ou seja, como produtos da interação complexa entre cognição e subjetividade, consciente e inconsciente. Isto significa que poderemos encontrar, como resultado dessa interação, práticas muitas vezes contraditórias entre si ou, até mesmo, em oposição às intenções e objetivos racionalmente planejados.

O problema torna-se ainda mais evidente quando o formador tem pouca experiência em lidar com os professores, apesar de, eventualmente, ter participado de cursos de formação avançados. Neste caso, o formador está numa posição delicada, pois ainda não conseguiu elaborar uma maneira segura de atuar, na qual possa depositar sua confiança para enfrentar os desafios da prática. A situação é, em parte, semelhante àquela que o jovem professor deve enfrentar no início de sua carreira docente.

Procurando contribuir com informações neste campo, analisamos a experiência de uma formadora de professores no início de sua carreira, evidenciando suas dimensões objetivas e subjetivas, no contexto de um curso de formação continuada para professores de química.

Foi por meio de entrevistas, dos diálogos mantidos entre a formadora e a pesquisadora nos momentos de preparação e avaliação dos encontros, além dos depoimentos dos professores participantes, que obtivemos as pistas para levantar a hipótese de que elementos subjetivos implícitos nas ações e reflexões da formadora estariam atuando de forma a resultar em contrastes entre sua prática e suas reflexões conscientes. Utilizando a técnica da associação livre, procuramos trazer à tona os elementos menos evidentes das ações da formadora, sobretudo aqueles que nos pareceram importantes, quando se trata dos efeitos que eles podem gerar nos professores em formação.

Em nossa interpretação, a prática reflexiva - tal como vem sendo crescentemente valorizada no campo da formação continuada de professores - deve considerar que o plano inconsciente atua e intervém nos pensamentos e nas ações dos sujeitos. Por isso, utilizandonos do referencial teórico da psicanálise em S. Freud e J. Lacan e de alguns de seus conceitos primordiais, propomo-nos alargar a ideia de reflexão, tomando-a como uma prática de questionamento das posições subjetivas dos sujeitos frente às situações que se lhes apresentam. Acreditamos que nossa análise possa auxiliar não somente os formadores que se encontram em condições semelhantes, mas também todos aqueles que podem ajudá-los nesta tarefa.

\section{Metodologia}

Os dados aqui apresentados foram coletados por meio de acompanhamento e participação da pesquisadora junto a um curso de formação, como coadjuvante, auxiliando a formadora Malu em todos os encontros com os professores. Nesse duplo papel, a pesquisadora pôde compartilhar das satisfações, bem como das angústias vivenciadas in loco, ao lado dos 
Altarugio, M. H.; Villani, A.

professores, e nos "bastidores", quando elas comentavam os eventos de cada dia de encontro. O foco desta pesquisa não está, portanto, no grupo de professores, mas na formadora. É na reflexão sobre sua ação, registrada em áudio, que vimos emergir suas ideias, conflitos, angústias, e impressões sobre as ações bem ou não tão bem-sucedidas, segundo ela mesma.

As falas transcritas foram retiradas das duas únicas entrevistas semiestruturadas realizadas, a saber, uma delas antes do final do curso e, a outra, logo depois do último encontro com o grupo. É importante assinalar que a proximidade e o estabelecimento de um clima de confiança progressivamente maior ao longo do curso, entre a pesquisadora e a formadora, não só deram condições à segunda de se expor mais livremente durante a entrevista, como à primeira de arrojar na sua interpretação.

Durante as entrevistas, Malu sentiu-se bastante à vontade e, embora tenhamos lançado mão das entrevistas semiestruturadas, a fala da formadora se deu de uma forma bastante livre. A fala, na psicanálise, é um evento da maior importância porque é no momento em que se fala que o sujeito experimenta o peso e o valor das suas palavras, e, muitas vezes, acontece de ele procurar se corrigir.

[...] a essa particularidade de o sujeito se ouvir quando ele mesmo fala e ao se ouvir se dividir, pois, por vezes, fala coisas que não queria, que não sabia (que sabia) e que o surpreendem como se fosse a fala de outrem. E também quando não escuta o que fala, principalmente quando é algo que ele não queria falar e, sem querer, fala. (QUINET, 2000, p. 44)

Essa foi uma oportunidade de colocarmos em prática estratégias com elementos análogos aos da técnica analítica - a associação livre e a escuta flutuante - como forma de trazer à tona os elementos menos evidentes das ações da formadora. Esses elementos nos pareceram importantes para se levar em conta, sobretudo quando se trata dos efeitos que podem ser gerados nos professores em formação.

Freud, partindo da hipótese de que a fala é o meio de expressão do conteúdo inconsciente, cria uma técnica que tem uma única regra, "a regra de ouro da psicanálise": a associação livre. Ainda que não estivéssemos diante de uma situação de análise, podemos dizer que a fala espontânea de um sujeito se constitui, sempre, em substrato fundamental a partir do qual emergem materiais riquíssimos para a reflexão, tais como sintomas, fantasias e desejos.

Para quem escuta - no caso, a pesquisadora -, cabe preparar-se para uma escuta sem preconceitos, desarmada. Essa escuta recebe o nome de atenção flutuante. Freud (1912) formula essa técnica explicitamente em "Recomendações aos médicos que exercem a Psicanálise", da seguinte maneira: "Consiste simplesmente em não dirigir o reparo para algo específico e em manter a mesma 'atenção uniformemente suspensa' em face de tudo o que se escuta" (p. 153). Novamente, embora não se tratando a situação de um setting analítico, mas fazendo uma aproximação com a posição do analista, ficamos abertos ao inesperado e prontos para deixar-nos surpreender.

Além das falas da formadora, aparecerão também transcrições das falas dos professores, coletadas em dois momentos nos quais foram solicitadas, ao grupo, avaliações a respeito do curso, por escrito. Os dados analisados são cenas ou situações que dão indícios de eventos repetitivos ou, de alguma forma, perturbadores, que propõem uma "novidade" que vale a 
pena ser investigada, nos quais a possibilidade de explorar o referencial psicanalítico se revela mais promissora e com chances de produzir conhecimento novo.

O caso analisado representa uma história particular, de modo que os recortes realizados ressaltam determinadas singularidades, aquelas que, subjetivamente, nos interessaram. Ao longo da análise, aparecem as falas dos sujeitos acompanhadas, primeiramente, dos comentários mais objetivos que dão sentido aos eventos. Depois, uma reflexão mais profunda tenta captar a essência de cada história, explorando as hipóteses mais prováveis que ajudariam a explicar e compreender melhor a posição subjetiva de cada sujeito, utilizando-se, então, os conceitos psicanalíticos que nos permitem interpretá-los.

Todos os dados coletados foram discutidos no nosso grupo de pesquisa ${ }^{3}$, cujo papel é procurar testar a coerência e a plausibilidade das interpretações primeiras. Também é função do grupo de pesquisa questionar, reorientar ou complementar essas interpretações.

\section{A proposta do curso}

O curso, intitulado "Encontros de Reflexão e Ação sobre a Sala de Aula de Química", foi oferecido e ministrado numa universidade pública durante o ano de 2004, totalizando sessenta horas. Com o propósito de iniciar uma parceria entre a universidade e os professores de Química da escola pública, este curso destinou-se a atender os seguintes objetivos: a) oferecer oportunidades para se aperfeiçoar e refletir sobre a prática de sala de aula; b) discutir os conceitos químicos presentes em temas de interesse social, como saúde, meio ambiente, e novos materiais; c) disponibilizar acesso a propostas de ensino envolvendo computador, internet e vídeo; d) debater as repercussões das pesquisas sobre educação em Química na sala de aula; e) formar grupos de trabalho para elaborar, aplicar e refletir sobre atividades de ensino.

As vagas oferecidas foram preenchidas por professores de Química (em sua maioria) e Biologia do Ensino Médio: o curso iniciou com 19 professores e encerrou com oito participantes. É importante considerar que não foi oferecido, aos participantes, nenhum tipo de incentivo monetário (bolsa de estudo, ajuda de custos), ou vantagens que são comuns nos cursos dessa natureza, como abono de ponto ou registro de hora-aula dentro de HTPC 4 . Os professores receberam apenas a garantia de um certificado de participação gerado pela universidade pela conclusão do curso.

Dentro da organização da proposta, a formadora fez a divisão dos trabalhos em dois semestres:

$1^{\circ}$ Semestre. A formadora apoiou seu trabalho no material denominado "Fármacos: um estudo químico, biológico e social", que ela produzira e aplicara, no ano anterior, para seus

\footnotetext{
${ }^{3} \mathrm{O}$ grupo envolvido que nos auxiliou na interpretação está envolvido de maneira estável com o referencial da psicanálise. Sua metodologia de pesquisa está descrita em Villani; Barolli e Arruda (2006).

${ }^{4}$ HTPC significa Hora de Trabalho Pedagógico Coletivo. Parte da carga didática dos professores é reservada para o desenvolvimento de projetos e atividades pedagógicas fora da sala de aula, na unidade escolar, sob a orientação do Coordenador Pedagógico.
} 
Altarugio, M. H.; Villani, A.

alunos do Ensino Médio. A proposta era explorar, com os professores, o eixo tema-conteúdoatividade a partir do qual estava estruturado esse material.

$2^{\circ}$ Semestre. A proposta para os professores era planejar e aplicar, em sala de aula, um módulo de ensino com base na estrutura discutida no semestre anterior.

\section{As angústias de uma formadora inexperiente}

Malu tinha completado o curso de licenciatura em Química numa Universidade Federal e atuado como professora do Ensino Médio na rede pública e particular. Também tinha participado dos encontros de um grupo de formação continuada, dentro da sua universidade, procurando aperfeiçoar seus conhecimentos em Química e Educação, onde teve oportunidade de trabalhar com materiais que contemplavam uma proposta alternativa dentro do ensino de Química. Na época dos eventos que analisaremos, Malu estava cursando o mestrado em Ensino de Ciências e pretendia explorar parte da nova experiência como formadora para elaborar sua dissertação.

A pesquisadora conheceu Malu por ocasião de um convite que recebeu para participar, como colaboradora, do curso de formação para professores que estava sendo idealizado. Aceitei o convite com a intenção de coletar dados para minha pesquisa de doutorado e poder continuar explorando o referencial da psicanálise no contexto da formação continuada de professores. Desde o início, nossa empatia foi muito grande e nos sentíamos muito à vontade. Ao observar suas ações junto ao grupo, Malu demonstrava segurança e firmeza, ao mesmo tempo, leveza e descontração. No entanto, em nossas conversas informais, acabávamos também expondo nossas dificuldades pessoais em lidar com essa tarefa. Assim, a imagem da Malu, segura de si, leve e descontraída diante dos professores, começou a dar lugar, nos bastidores, a uma figura um pouco mais angustiada, preocupada e cercada de incertezas. Malu buscava, cada vez mais, a minha colaboração, pedindo e acatando minhas sugestões. Desse modo, aumentavam os indícios que revelavam a efetiva inexperiência de Malu como formadora, embora não o pudesse afirmar com certeza.

Entretanto, o que me chamou a atenção foi esse contraste entre o espírito desarmado, solto, leve, descontraído da formadora, na condução das atividades, e a tensão que ela deixava transparecer, aos poucos, nos momentos de reflexão sobre a própria prática. Como conciliar esses dados? De um lado, a insegurança, a falta de experiência que pareciam suficientes para comprometer seu desempenho, e, de outro, porém, uma ação que caminhava na direção oposta, que não delatava sua fragilidade.

Diante desses dados, minha hipótese era a de que a presença de alguns elementos, atuando de maneira inconsciente para Malu, estivesse na origem dos pontos de tensão e, também, influenciasse sua serenidade. A pesquisadora propôs a primeira entrevista para a formadora após seis meses de trabalho. Foi somente nessa ocasião que Malu revelou:

"Nunca tinha pensado em trabalhar com professores. Nunca tinha trabalhado. Eu já tinha participado de cursos de formação (como aluna). Eu não tinba nada de preparação, de concepşão, nunca tinha pensado em formação, em como trabalhar com professores, nada." 
Nessa fala, Malu declara sentir-se pouco preparada para a tarefa, apesar de seu orientador ter participado do planejamento inicial e dos primeiros encontros para dar seu apoio às iniciativas da formadora. Várias vezes, nas reuniões após os encontros, ela manifestou sua insatisfação por sua condução, queixando-se, sobretudo, de seu planejamento pouco detalhado. Enfim, parecia-lhe não ter um controle suficiente e isso a deixava insegura, até por permitir espaços para desvios do eixo do curso. Entretanto, para a surpresa de Malu e da própria pesquisadora, as opiniões dos professores, em avaliações individuais, parecem apontar para leituras ortogonais em relação às preocupações de Malu:

"Quero aproveitar para enfatizar o profissionalismo com que vocês [formadoras] nos tratam, escutando e levando em consideração as nossas ansiedades e dúvidas. $O$ diferencial desse curso foi a liberdade que nós tivemos de programarmos um projeto."

"Elas [formadoras] têm facilitado a convivência e as discussões, criando um clima de cordialidade e ambiente muito agradável, no qual todos podem expor suas idéias e trocar experiências."

"As capacitadoras e os colegas do grupo tornaram-se parceiros e colaboram entre si. Isso é muito bom para o crescimento profissional de todos. O curso também proporcionou troca de experiências entre colegas e a somatória de estímulos para a continuidade dessa jornada. O curso possui um diferencial que é o caminhar de acordo com nossas realidades."

Percebe-se, de um lado, a liberdade, a troca de experiências, a parceria, a colaboração, a escuta, o clima cordial, o ambiente agradável, o estímulo, o caminhar de acordo com a realidade, salientados pelos professores participantes. De outro lado, a insegurança, a falta de experiência e a sensação de perder o controle do curso, declaradas por Malu:

"Nos primeiros dias eu estava bem nervosa e estava preocupada em seguir o conteúdo, o cronograma. A gente tinha um planejamento. Eu estava pensando como que o meu orientador gostaria que aquela aula acontecesse e não como eu levaria a aula”.

Nossa interpretação é de que a angústia de Malu era gerada, inicialmente, pelo confronto com um ideal de formação elaborado, imaginariamente, a partir das expectativas de um formador experiente, no caso, seu orientador, e da pouca confiança em si mesma. Porém, esse ideal de controle não operava durante a atuação com os professores, pelo menos, de um modo que fosse percebido por parte do grupo e por parte da pesquisadora:

"Eu achei que a proposta dele (orientador) era para o nosso grupo (orientandos) dar aula. Estava achando que cada um ia pegar uma parte. Quando eu vi que eu ia assumir o curso todo sozinha, eu fiquei preocupada, tensa mesmo. Tanto você viu que ele (orientador) veio, participon de dois ou três encontros, depois saiu fora. Eu falei: vou levar do jeito que eu sei." 
Altarugio, M. H.; Villani, A.

Sem dúvida, Malu tinha, como sua referência, o orientador, para o qual ela prestava contas conscientemente em suas reflexões e, provavelmente, de maneira inconsciente, na sua atuação. Nesse sentido, o orientador representava, para ela, o Outro da psicanálise (grande Outro $)^{5}$, ou seja, a referência implícita da criança, introduzida quando de sua entrada na linguagem. Em nosso caso, ao sujeitar-se ao orientador, ao considerá-lo como seu guia e seu modelo implícito, Malu ganhava cidadania na Academia. Entretanto, parece-nos possível interpretar que o orientador, de alguma forma, conseguiu ajudá-la a avançar, revertendo o processo de dependência inconsciente: ao depositar toda confiança nela, deixando-a assumir a tarefa sozinha, conseguiu que ela imprimisse um toque pessoal ao curso, descolado de um ideal que ela supôs estar no seu orientador.

É interessante notar que a operação realizada pelo orientador não constitui uma regra para ajudar o orientando a tornar-se mais autônomo, a adotar um estilo próprio. O 'abandono' dele, ao invés de ser interpretado como um sinal de confiança poderia ter tido um efeito paralisante e um convite a não se afastar do planejamento e da imitação do orientador. De fato, esta preocupação, por um longo tempo, ocupou a reflexão de Malu, gerando um descompasso entre os sentimentos que acompanham a realização da docência e a sucessiva reflexão. Esse efeito é bastante comum em docentes que iniciam um contato sistemático com a literatura sobre educação e pretendem entrar na Academia. Em alguns casos, também aparece a divisão entre a reflexão baseada no ideal e a atuação baseada na intuição docente (SUDAN, 2005).

Outro ponto de tensão que Malu revela em suas reflexões está localizado em sua falta de domínio em relação a determinados conteúdos que, eventualmente, poderiam ser abordados e exigidos pelo grupo durante o curso. Malu demonstra um receio em mostrar falhas nesse sentido.

"A única coisa que en fiquei pensando: será que eles vão ficar questionando muito? Se eles começassem a perguntar de teorias da educação, eu acho que ia me enrolar. Isso ai eu tava com certo receio. Mas quando a gente foi faz̧er a organização das aulas eи vi que eu não ia entrar muito nesse campo, que era essa a minha insegurança no início. Como eu vou dar conta disso? Como que eu vou dar aula de teoria e eu acho que eu não tenho essa condição de chegar, entrar num curso e dar teoria de educação, eu não tenho esse conbecimento."

Entretanto, esta preocupação não perturbava sua maneira de conduzir o curso, bloqueando eventuais demandas dos professores. Nesse caso, como revelou num comentário informal, ela confiava muito na competência da pesquisadora que a acompanhava, para a qual delegou algumas intervenções nesse sentido.

Quando questionada sobre suas expectativas iniciais a respeito do grupo de professores que estaria frequentando o curso, Malu não pontuou nenhuma preocupação em especial.

\footnotetext{
5 Ao longo da obra de J. Lacan, o Outro vai adquirindo várias acepções. Neste caso, utilizamos a acepção de Outro como discurso, que Lacan apresenta no Seminário 11 (LACAN, 1979). 
A experiência de uma formadora de professores ...

"Sobre concep̧cões dos professores, eu não tinha idéia, por exemplo, dessa questão das reclamações. A gente não tinha nos grupos, nem nos HTPCs, nem na universidade, durante os dois, três anos que eu fiquei lá dentro, não tinha essas reclamações não. Eram professores de escola pública, de escola particular. O que era discutido era tudo aceito, tudo tranqüilo, a gente não tinha esses embates: "isso aí não dá pra aplicar, não dá pra fazere’".

Nessa fala, Malu se recorda dos grupos de formação dos quais participou como aluna nos tempos em que permaneceu ligada à universidade, dos quais trouxe experiências altamente positivas. Pensamos que essas experiências permitiram que ela construísse uma visão a respeito de professores muito otimista e favorável ao seu trabalho posterior como formadora de professores. $O$ fato de não ter elaborado expectativas tornou desnecessário pensar em esquemas de defesa em relação aos professores que iriam chegar. Mrech (1999) ressalta que um discurso prévio, que antecede o contato do sujeito com a realidade com a qual ele vai lidar, é criado no imaginário dos sujeitos e, junto com ele, formas de ação socialmente determinadas que estruturam o que escutar, o que dizer e o que fazer em um determinado momento.

Malu estava consciente de sua maneira de lidar com os professores:

"O professor teve toda a liberdade de estar fazendo o planejamento dele. Primeiro a gente escutou, ouviu como eles planejam, como eles desenvolvem. Por exemplo, a diferença do professor Davi e da professora Magda, eu percebo a diferença. Da professora Geisa eu não percebo muito não. Eles trabalharam o mesmo projeto mas cada um na sua realidade."

A oportunidade dada aos professores de caminharem de acordo com a realidade entende-se como resultado da percepção da formadora, que ficou atenta às singularidades de cada um. A realidade precisa ser entendida aqui sob dois aspectos: um deles refere-se ao mundo concreto, material, externo ao sujeito, que, no caso, representa a escola, os alunos, a sociedade da qual eles fazem parte. Em psicanálise, chamamos esse quadro de realidade material, social ou externa, na concepção freudiana. A formadora tem noções dessa realidade, não apenas por meio da fala dos professores, mas também porque fez contato com ela quando exerceu sua atividade como professora de escola pública. A outra noção de realidade, a psicanálise chama de realidade psíquica, que é a leitura que cada sujeito faz da realidade concreta. Por ser uma leitura particular dos sujeitos, essa é mais difícil de ser capturada (ALTARUGIO, 2002).

A formadora parece estar atenta aos sujeitos, ouvi-los, porque, embora eles possam compartilhar de uma mesma realidade externa, cada qual age segundo sua realidade psíquica, ou seja, com seu modo particular de abordagem e posicionamento frente a ela.

Outro detalhe que nos permite entender a ausência de defesas na relação entre Malu e os professores é sua experiência anterior com o Ensino Médio. Ela tinha produzido e aplicado, para seus alunos, o mesmo material levado ao curso de formação. Isso tinha permitido desenvolver um conjunto de atividades consideradas interessantes pelos alunos: debates, leitura, experimentos e vídeos acerca dos conteúdos químicos, biológicos e sociais associados ao material. Malu considerava sua experiência um sucesso e acreditava que os professores poderiam aproveitar, com vantagens, do mesmo material em suas salas de aula. 
Altarugio, M. H.; Villani, A.

Essa convicção, além de gerar confiança na formadora, também ia ao encontro de uma expectativa dos professores do curso que, desde o início, manifestaram sua crença na possibilidade de apreenderem um modo "correto" de ensinar, possivelmente corporificado num método ou numa "receita". Essa suposição, bastante comum nos professores que frequentam cursos de capacitação buscando metodologias novas, leva-os a uma outra crença: a de que os formadores possuem o domínio desse conhecimento. Essa posição assumida pela pessoa do formador, com qual o professor se identifica, é denominada, pela psicanálise, de Sujeito Suposto Saber, aquele que, imaginariamente, seria o depositário do saber que deverá resolver os seus problemas. A identificação é necessária no início do processo, para que se dê o movimento do sujeito na direção do aprender. No entanto, com o tempo, o professor deverá perceber que lhe cabe encontrar seu caminho pessoal, dissociar-se do saber do formador e tornar-se autônomo.

Malu articulou as atividades do curso, em sua primeira metade, com o material que ela produziu mediante discussões acerca do tema (utilização de um medicamento fitoterápico), e das atividades que poderiam ser realizadas. Ao apresentar o seu material para o grupo, a formadora parecia ter em mãos a tão esperada "receita", o conhecimento que supostamente estaria depositado no Sujeito Suposto Saber. Assim, o material serviu como um modelo, porém Malu teve o cuidado de não impor sua adoção em sala de aula por parte dos professores, mantendo, simultaneamente, o clima de liberdade e de segurança. Isso permitiu que duas professoras, que trabalhavam na mesma escola, resolvessem aplicá-lo com seus alunos sob a supervisão de Malu.

"Trouxemos as professoras para o curso de formação, apresentamos a nossa proposta, negociamos as atividades. Elas não queriam trabalhar com trechos de filmes - foi a unica coisa que foi imposta - levei para elas os trechos, não levei o filme inteiro e elas usaram, gostaram. Mas foram elas que fizeram o planejamento, a divisão de aulas, elas que fizeram tudo, quantas turmas elas iriam usar, quais os dias, tudo isso foi feito por elas, elas que organizaram. E eu estava lá meio que... tentando, fazendo com que elas cumprissem."

Malu não deixou de questionar e discutir, com o grupo, os problemas que enfrentaram e as possíveis alternativas para solucioná-los. Compartilhava com os professores suas próprias dúvidas, incertezas e questões de sala de aula. Talvez tenha surgido, aí, uma identificação do grupo com a formadora e, por isso, o depoimento das professoras que sentiram as capacitadoras como parceiras e colaboradoras do grupo. Outras puderam vivenciar suas próprias questões ao aplicarem o material, e mostraram-se satisfeitas com o resultado.

"Eu e minha colega tivemos a sorte de aplicar o projeto da Malu em nossa escola. Foi uma experiência muito prazerosa onde pudemos utilizar vários recursos didáticos (sala de informática, laboratório, filme, debates e pesquisas). A grande maioria participou e desenvolveu as atividades propostas."

"A parceria foi muito boa, tanto a Malu como a estagiária nos apoiaram muito. Pudemos reformular o projeto 'Convivendo com as Calorias' baseado no projeto 'Fármacos', o que para nós foi muito interessante e nos deu a possibilidade de recriar o que já trabalhávamos." 
No $2^{\circ}$ semestre do curso, a proposta para o grupo foi a elaboração de um módulo de ensino com escolha livre das séries para as quais seria aplicado, do número de aulas necessário, na condição de seguir a estrutura tema-conteúdo-atividade. O planejamento do módulo se deu durante dois meses de encontros, acompanhado pela formadora, e a aplicação ficou reservada para os dois últimos do curso.

Algumas professoras, estimuladas a elaborarem um outro projeto, ainda que baseado no material de Malu, começaram a dar os primeiros passos na direção da autonomia, da dissociação do saber da formadora.

"As dificuldades enfrentadas ficam para a aplicação dos projetos, pois o horário e a época do ano que esta aplicação precisa acontecer às vezues não são possíveis por causa dos feriados e outras atividades desenvolvidas pela escola."

"As dificuldades que en vejo para realizar estes projetos na escola são: a falta de infra-estrutura, a resistência de alguns professores em participar, a aquisição de material. Para vencer os obstáculos a parceria com a universidade é fundamental."

\section{Nem tudo funciona como o desejado}

Acompanhando o grupo na elaboração do módulo, Malu se preocupou quando percebeu a dificuldade das professoras para se envolverem com o trabalho. Sobre isso ela reflete:

"Eu cheguei a semana passada e pensei: gente, mas eu tenho que cobrar (dos professores) alguma coisa, né. E quem vem aqui, senta e não faz nada? Não vai fazer nada? Porque tem dia que eu acho que eu não cobro."

Ao contrário da postura descontraída e desarmada que Malu adotou em relação aos professores no início do curso, chegou um momento em que ela necessitou resgatar sua posição de mestre. No entanto, tomar a decisão de assumir uma postura mais autoritária cobrando um maior envolvimento dessas professoras, como ela entendia ser o seu papel, não se mostrou uma tarefa fácil na prática.

"A gente pediu para eles planejarem o módulo de ensino. O que Ilda está fazendo não é módulo de ensino, o que Bete está fazendo não é módulo de ensino. E aí, como é que eu chego? Uma pessoa sozinha numa escola, cheia de dificuldades, vou apertar ela como? Não sei como é que eu faço isso! Me incomoda, sabe. Ai eu fico pensando se eu estou fazendo de conta para ela que eu estou criticando, que aquilo ali é o módulo de ensino. E se ela não entendeu que tinha que fazer um módulo de ensino? Ou se ela entendeu que tinha que planejar mais uma atividade? Porque quando ela pôs no papel ali, eu pensei: isso aqui não é módulo de ensino. Mas aí ela me falou que já aplicou o módulo na sua sala de aula!" 
Altarugio, M. H.; Villani, A.

Ao mesmo tempo, Malu sentiu que a situação era delicada e confessou não saber como agir. A formadora tinha, como pressuposto, o respeito à liberdade individual dos professores, tanto no planejamento, quanto na implementação dos seus projetos. Mas como diz Rosa (1996), sobre os desafios da mudança diante de uma perspectiva construtivista, não pode haver confusão, comum aos professores, entre manter um ambiente de liberdade de expressão e eximir-se de direção. Pensamos que podemos transpor o comentário para a situação da formadora em relação às professoras Ilda e Bete.

O que Malu estava questionando nesse momento não era somente o seu papel de formadora, mas como e qual a melhor maneira de exercê-lo. Sobre esse papel, o fato de se

afirmar que os professores, por si mesmos, devem reconhecer, avaliar e decidir não implica que se está diminuindo o papel da pessoa orientadora, já que ela tem a difícil e importante função de promover as atividades que possibilitem o reconhecimento, a avaliação e tomada de decisões. (COPELLO LEVY; SANMARTÍ PUIG, 2001, p. 277)

"É complicado. Você vai tratar o professor como um aluno, vai chamar a atenção? Eu tenho que chegar para o professor e falar assim: você não está cumprindo o combinado, ou, você não atingiu a meta. Não sei."

A dificuldade de Malu em ocupar e sustentar a posição de Mestre no Saber ${ }^{6}$ talvez esteja associada ao fato de ela não ter clareza do seu papel na relação formador-professor. Para ela, a relação ainda ficava no nível professor-professor, o que tornava desconfortável uma ação de chegar no professor, chamar sua atenção, como ela colocou. Mesmo insegura, a formadora tentou uma saída possível, aproximando-se de Ilda no momento que julgou mais oportuno: quando Ilda comentava sobre a dificuldade de seu aluno em relação a alguns conceitos químicos, mas não conseguia ajudá-lo. No entanto, Malu não encontrou reciprocidade:

"Eu pensei: eu vou dar um texto sobre elemento quimico para ela. Ai eu dei uma olhada no texto e pensei: não vou dar. Ai ela falou sobre o livro didático. Então, eu busquei como se fosse interesse meu, fui buscar (o assunto) nos livros didáticos, ver o que cada um falava, mas ela não se interessou. Ela foi lá e guardou os livros. É como se: 'essa conversa não é comigo'. Deixou nós duas ali discutindo e fez que não era com ela!"

Para Monteiro (1999), a autoridade é a diferença necessária à relação professor-aluno. Segundo ela, a aprendizagem será realmente efetivada se o professor sustentar-se no lugar em que é colocado pelo aluno, ou seja, na posição de quem conhece o seu desejo, pelo menos até

${ }^{6}$ A expressão Mestre no Saber está relacionada ao Discurso do Mestre, um dos quatro discursos (do Mestre, da Universidade, do Analista e da Histérica) que Lacan trabalha de forma mais acentuada em seu Seminário 17 (LACAN, 1992). 
que se instaure a "transferência pedagógica" e se inicie o processo de separação, com a elaboração de um saber próprio e, de alguma forma, autônomo.

Apesar das dificuldades encontradas, Malu considerou que a experiência foi positiva para ela e para os professores que participaram do curso. Mais do que isso, percebeu que o grupo estava avançando na perspectiva de elaborar seus próprios planejamentos. Assim, resolveu atender aos pedidos dos professores e dar continuidade ao trabalho de formação, apostando na expectativa de manter o grupo unido e crescendo.

\section{Considerações finais}

A observação e análise da prática e das reflexões da formadora revelaram-nos a existência de dois contrastes básicos. O primeiro mostra uma formadora insegura, em conflito, angustiada diante de situações novas para ela, naturalmente considerando a sua inexperiência no trato com professores. No entanto, esse mal-estar parece não afetar sua atuação, ao contrário, ela parece conduzir o curso de forma solta, leve e descontraída. Esse fato, que nos chamou a atenção, levou-nos a indagar e a supor a existência de elementos não evidentes que estariam dando suporte à prática da formadora. Em nossa investigação, foi possível trazer à tona alguns elementos ou fatores que, ao nosso olhar, estariam servindo-lhe como apoio, ainda que de forma inconsciente para a formadora. Tais elementos, identificamos como sendo: a confiança no seu material, a confiança advinda do seu orientador, o apoio da pesquisadora-colaboradora, as experiências positivas adquiridas ao longo de sua formação, a ausência de concepções prévias estereotipadas em relação ao grupo de professores, além do objetivo claro de explorar parte da nova experiência para elaborar sua dissertação.

O segundo contraste aparece quando ela revela, em suas reflexões, a necessidade clara de resgatar sua posição de mestre. No entanto, durante o ato de enfrentar uma situação que lhe exige uma postura mais firme, Malu acaba não conseguindo - apesar da tentativa sustentar-se em sua posição de mestre. Também nesse caso, supomos a existência de elementos não evidentes, que pudessem explicar a ação da formadora na direção oposta de sua reflexão. Nossa hipótese é de que a possível presença de um conflito, atuando sobre o papel da formadora e sua identidade como tal, não permitia a ela diferenciar-se do professor com o qual estava lidando, exercendo sobre ele a autoridade necessária.

Nossas conclusões apontam para a complexidade da situação na qual se encontrava Malu: a relação entre a reflexão consciente da formadora e sua atuação na prática revela contrastes, nos mostrando que não necessariamente atuam na mesma direção. É o referencial psicanalítico que nos auxilia, nesse momento, a compreender, numa dimensão subjetiva, mais precisamente do inconsciente, os desvios entre a reflexão consciente e a ação da formadora. $O$ jogo do inconsciente se mostra surpreendente, quando, uma vez, atua a favor da situação, possibilitando à formadora uma condução leve e descontraída do curso, e quando, outra vez, atua contra, dificultando a sustentação de seu papel de mestre. Nesse sentido, acreditamos que uma reflexão mais profunda, por parte de Malu, e com a ajuda dos seus diálogos com a pesquisadora, nos ajudou a investigar, não apenas sobre a sua prática, mas sobre o sujeito que ali estava implicado, sobre suas resistências, medos e desejos. 
Altarugio, M. H.; Villani, A.

Sem dúvida, a situação da formadora no início de sua carreira como docente de professores ampliou os conflitos e as dificuldades por ela enfrentadas. Entretanto, acreditamos que essa peculiaridade ajudou a revelar a presença de problemas comuns nos cursos de formação continuada, apesar de menos evidentes. Acreditamos que os jogos do inconsciente não atuam somente no caso de formadores no início de carreira. Assim, no contexto mais amplo da formação de professores, tal qualidade de reflexão pode revelar-se mais eficaz na medida em que pode trazer à tona elementos menos conscientes, com os quais os sujeitos, tanto os professores quanto os formadores, podem aprender a lidar e transformar suas práticas, com a possibilidade de produzirem efeitos melhores em suas atividades docentes.

\section{Referências}

ALTARUGIO, M. H. "Este curso não se adapta à minha realidade": os conflitos de um grupo de professores de química em formação continuada. 2002. 144f. Dissertação (Mestrado em Ensino de Ciências) - Faculdade de Educação, Universidade de São Paulo, São Paulo, 2002.

COPPELO LEVY, M. I. L.; SANMARTÍ PUIG, N. Fundamentos de um modelo de formación permanente del profesorado de ciencias centrado en la reflexión dialógica sobre las concepciones y las prácticas. Enseñanza de las Ciencias, Barcelona, v. 19, n. 2, p. 269-283, 2001.

FREUD, S. Recomendações aos médicos que exercem a Psicanálise: obras psicológicas completas de Sigmund Freud, 1912. Rio de Janeiro: Imago, 1980. (Edição Eletrônica Brasileira, v. 12, cd-rom).

GUNSTONE, R. F.; NORTHFIELD, J. Metacognition and learning to teach. International Journal of Science Education, London, v. 77, n. 1, p. 523-537, 1994.

LACAN, J. O seminário, livro 17: o avesso da psicanálise. Rio de Janeiro: Jorge Zahar , 1992.

O seminário, livro 11: os quatro conceitos fundamentais da Psicanálise. Rio de Janeiro: Jorge Zahar, 1979.

LAJONQUIÈRE, L. De Piaget a Freud: a (psico)pedagogia entre o conhecimento e o saber. 5. ed. Petrópolis: Vozes, 1992.

MONTEIRO, E. A. A transferência e a ação educativa. In: COLÓQUIO DO LUGAR DE VIDA/LEPSI, 1., 1999, São Paulo. Anais... São Paulo: USP , 1999. p. 171-189.

MRECH, L.M. Psicanálise e educação: novos operadores de leitura. São Paulo: Pioneira, 1999. 
A experiência de uma formadora de professores ...

PERRENOUD, P. Práticas pedagógicas e profissão docente: três facetas. In:

Práticas pedagógicas, profissão docente e formação: perspectivas sociológicas. Lisboa: Dom Quixote, 1993. p. 17-31.

QUINET, A. A descoberta do inconsciente: do desejo ao sintoma. Rio de Janeiro: Jorge Zahar, 2000.

ROSA, S. S. Construtivismo e mudança. 4. ed. São Paulo: Cortez, 1996.

SÁNCHEZ BLANCO, G.; VALCÁRCEL PÉREZ, M. V. Qué tienen en cuenta los profesores cuando seleccionan el contenido de enseñanza? Cambios y dificuldades tras un programa de formación. Enseñanza de las Ciencias, Barcelona, v. 18, n. 3, p. 423-437, 2000.

SUDAN, D. C. Saberes em construção de uma professora que pesquisa sua própria prática. 2005. 262f. Dissertação (Mestrado em Educação) - Departamento de Educação, Universidade Federal de São Carlos, São Carlos, 2005.

VILLANI, A.; BAROLLI, E.; ARRUDA, S. M. Contribuições da Psicanálise para uma Metodologia de Pesquisa em Educação em Ciências. In: SANTOS, F. M. T.; GRECA, I. M. (Orgs.). A pesquisa em ensino de Ciências no Brasil e suas metodologias. Ijuí: Ed. Unijui, 2006. p. 323-390.

Artigo recebido em agosto de 2010 e aceito em novembro de 2010. 